\title{
Busão: um Sistema de Informações Móvel para Auxílio à Mobilidade Urbana Através do Uso de Transporte Coletivo
}

\author{
Daniel Farias Batista Leite, Júlio Henrique Rocha, Cláudio de Souza Baptista
}

Laboratório de Sistemas de Informação - Departamento de Sistemas e Computação Universidade Federal de Campina Grande(UFCG)

Rua Aprígio Veloso, 882 - Bairro Universitário, Campina Grande, Paraíba, Brasil

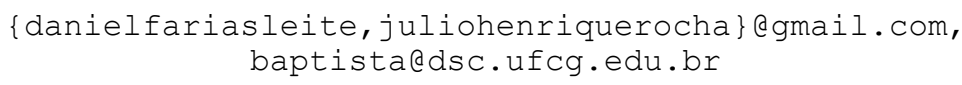

\begin{abstract}
With most of the population living in urban area, the preoccupation of the authorities and the population is increasing aiming to reduce the negative impacts caused by this urban agglomeration. One of the biggest challenges is to improve efficiency of the public transportation. Smart Cities applications and User Information System (UIS) have been increasingly used to optimize these transportation services. This paper presents the Busão, a mobile UIS that uses geoprocessing techniques based on users' location, point of interests and bus routes to present real time information about buses available in cities.
\end{abstract}

Resumo. Com grande parte da população brasileira residindo em zonas urbanas, cresce a preocupação das autoridades e da população para mitigação dos impactos negativos causados por esta aglomeração urbana. Um dos grandes desafios desse processo é a melhoria da eficiência dos transportes coletivos. Aplicações em Cidades Inteligentes e Sistema de Informação ao Usuário (SIU) são cada vez mais utilizadas para otimização desses serviços de transporte. Este artigo apresenta o Busão, um SIU móvel, que visa apoiar os usuários de ônibus, fornecendo informações em tempo real sobre os onnibus disponiveis na cidade, através de técnicas de geoprocessamento baseadas na localização dos usuários, pontos de interesse e rotas dos ônibus.

\section{Introdução}

De acordo com o Censo $2010^{1}$, o número de pessoas que residem em áreas urbanas continua crescendo, representando $84 \%$ da população brasileira. No entanto, a infraestrutura urbana não vem acompanhando este crescimento populacional vertiginoso, trazendo prejuízos à qualidade de vida dos cidadãos. Particularmente, a mobilidade urbana é um dos grandes gargalos nas médias e grandes cidades, uma vez que, a cada dia, cresce o número de veículos em circulação, resultando em vários trechos de engarrafamentos nas cidades.

\footnotetext{
${ }^{1} \mathrm{ftp}: / / \mathrm{ftp}$.ibge.gov.br/Censos/Censo_Demografico_2010/Resultados_do_Universo/tabelas_pdf/tab1.pdf, acessado em 08 de dezembro de 2012.
} 
Uma parte da solução para este problema é investir em transporte de massa, multimodais, onde faz parte, em grande maioria, o sistema de transporte coletivo urbano. Tal modalidade de transporte dá-se, na maioria das cidades, através do uso de ônibus, que, particularmente no Brasil, tem provido um serviço de baixa qualidade e ineficiente, o que leva a não atração ao mesmo por parte da população que detém veículos particulares.

Nesse contexto, a Tecnologia da Informação (TI) tem ajudado na proposição de sistemas de transporte inteligentes, que visam uma melhoria dos serviços prestados [Sussman 2005], [Wilson 2009]. Ademais, o advento de aplicações de sistemas de Cidades Inteligentes - um conjunto de sistemas públicos e privados independentes, que a cidade pode integrar e otimizar para alcançar um nível de eficácia e eficiência [Naphade et al 2011] - e Sistemas de Informações aos Usuários (SIU) - ferramentas de comunicação entre os operadores/gestores do transporte público e os usuários, sendo possível fornecer informações que satisfaçam as necessidades específicas dos usuários [Schein 2003] - apresentam-se como aliados na melhoria da infraestrutura do serviço de transporte coletivo.

Esses sistemas têm por objetivo melhorar a interação com o usuário, fornecendolhe informações acerca do serviço, tais como horários, tempo de viagem e de espera, localidades atendidas e outras informações relacionadas.

Paralelamente, vale destacar os avanços tecnológicos na telefonia móvel, tanto em infraestrutura como nos equipamentos como os smartphones. Tais equipamentos estão se tornando cada vez mais populares e trazem, dentre outras coisas, bons processadores, capacidade de armazenamento cada vez maior, acesso à internet e GPS embutido. Tais características permitem a provisão de sistemas de informação que fazem uso da mobilidade do usuário, permitindo um acesso em qualquer horário $\mathrm{e}$ lugar.

Este artigo propõe um novo SIU, para smartphones, denominado Busão ${ }^{2}$. O Busão tem por objetivo permitir aos usuários o acesso aos itinerários dos ônibus de cidades do Brasil. Para isso, faz uso de informações sobre as rotas do ônibus e leva em consideração a atual posição geográfica do usuário para indicar a(s) melhor(es) rotas para o usuário alcançar o seu destino. Além disso, o Busão também oferece outros serviços, como, por exemplo, rotas que levam aos pontos turísticos da cidade (POIs), tarifa praticada na cidade e os horários sobre as rotas.

O restante deste artigo está organizado como segue. Na seção 2, são apresentados alguns trabalhos relacionados à SIU. Na seção 3, apresenta-se uma descrição do Busão, contemplando sua arquitetura, os serviços de pesquisa por rotas propostos e a formalização do cálculo de espera para o próximo ônibus. Na seção 4, um estudo de caso, na cidade Campina Grande, Paraíba, é descrito. Por fim, na seção 5, são apresentadas as conclusões e os trabalhos futuros.

\footnotetext{
${ }^{2}$ https://play.google.com/store/apps/details?id=br.edu.ufcg.dsc
} 


\section{Trabalhos Relacionados}

Aplicativos e serviços que fornecem informações sobre transporte coletivo estão disponíveis em muitas cidades em todo o mundo. Vieira et al. (2012) e Lima et al. (2012) desenvolveram o Unibus, um serviço disponível para a cidade de Recife que utiliza informações providas pelo Twitter para recomendar rotas aos usuários, informando o tempo total do percurso. Liu B. et al. (2007) também propuseram um sistema que informa o tempo total do percurso entre dois pontos; mas leva em consideração as informações estáticas sobre a rota e informações de tráfego em tempo real, obtidas por dez mil dispositivos GPS equipados em táxis na cidade de Pequim. No entanto, nenhum desses sistemas comunica aos usuários o tempo restante para 0 próximo ônibus.

Amorim et al. (2012) propuseram um experimento para equipar táxis com dispositivos GPS registrando a localização a cada minuto. Porém o experimento só objetiva construir a trajetória do veículo durante o dia, e não dá suporte ao usuário para o mesmo escolher uma melhor rota. Também esta solução não é voltada para o transporte de massa.

Ferris et al. propuseram o OneBusWay (2010). O serviço, oferecido na cidade de Seattle, acessível pela web e por celulares, possibilita aos usuários a pesquisa por rotas pelo identificador dos ônibus, endereço ou por pontos de ônibus. A partir da consulta, o serviço indica a hora de saída de um dado ônibus nos pontos que o mesmo transita, indicando o tempo de atraso, caso exista, do ônibus. As informações são coletadas da agência oficial de transporte da cidade de Seattle, que dispõe de dados extraídos em tempo real dos ônibus da cidade, equipados com GPS.

Os trabalhos relacionados encontrados na área só permitem um tipo de consulta: a pesquisa informando o número da linha do ônibus ou um endereço qualquer. ChakchaiSo-In et al (2011) inovaram e criaram um SIU que utiliza uma versão otimizada do algoritmo de Dijkstra para recomendar rotas aos usuários, a partir de informações textuais sobre a origem e o destino desejados.

O presente trabalho apresenta um SIU que além de oferecer a pesquisa por linhas também possibilita a consulta por dois pontos selecionados pelo usuário, onde um dos pontos pode ser a posição atual do usuário - através da captura das coordenadas do GPS. Ademais, o Busão informa, de maneira intuitiva, os ônibus que têm como destino os pontos turísticos (POIs) da cidade. Na Tabela 1 ilustramos o comparativo entre os aplicativos disponíveis.

Tabela 1. Comparativo entre os aplicativos

\begin{tabular}{c|ccc}
\hline & Tipos de Pesquisas & $\begin{array}{c}\text { Captação de } \\
\text { sinal GPS }\end{array}$ & $\begin{array}{c}\text { Tempo restante para } \\
\text { próximo ônibus }\end{array}$ \\
\hline $\begin{array}{c}\text { Unibus } \\
\text { (Recife) }\end{array}$ & Pesquisa por Linha & - & $\begin{array}{c}\text { Informa tempo total do } \\
\text { percurso }\end{array}$ \\
$\begin{array}{c}\text { OneBusWay } \\
\text { (Seattle) }\end{array}$ & Pesquisa por Linha & $\begin{array}{c}\text { Captação } \\
\text { GPS dos } \\
\text { Ônibus }\end{array}$ & $\begin{array}{c}\text { Indica tempo de atraso } \\
\end{array}$ \\
\hline
\end{tabular}




\begin{tabular}{|c|c|c|c|}
\hline $\begin{array}{l}\text { ChakchaiSo } \\
\text {-In et al }\end{array}$ & $\begin{array}{l}\text { Pesquisa entre dois pontos } \\
\text { (de forma textual) }\end{array}$ & - & - \\
\hline $\begin{array}{l}\text { Busão } \\
\text { (Campina } \\
\text { Grande) }\end{array}$ & $\begin{array}{l}\text { Pesquisa por Linha e } \\
\text { pesquisa entre dois pontos } \\
\text { (utilização de GPS) }\end{array}$ & $\begin{array}{l}\text { Captação da } \\
\text { localização } \\
\text { geográfica } \\
\text { do usuário }\end{array}$ & $\begin{array}{l}\text { Indica tempo restante para } \\
\text { o próximo ônibus }\end{array}$ \\
\hline
\end{tabular}

\section{O Sistema de Informação Busão}

Essa seção introduz o Busão, um SIU para visualização de informações sobre as rotas de ônibus em um Mapa. O referido sistema foi desenvolvido para a plataforma Android e utiliza algumas funcionalidades oferecidas pela API do Google Maps. O Busão foi premiado em terceiro lugar, dentre 1.300 inscritos, no concurso nacional Campus Mobile $^{3}$ do Instituto Claro, em sua primeira edição, o que referendou sua proposta inovadora.

A ideia do Busão é permitir aos usuários terem acesso às rotas dos ônibus das cidades de uma forma intuitiva e com visualização amigável, através de mapas do Google Maps. Os usuários do transporte coletivo podem realizar a consulta em duas modalidades: Pesquisa por Linha e Pesquisa por Pontos, a serem detalhadas mais à frente.

Além disso, o Busão oferece algumas outras funcionalidades. O usuário terá conhecimento do preço da tarifa para aquela cidade e também as linhas que têm como destino os pontos turísticos da cidade. Nessa última funcionalidade, é possível fazer o compartilhamento da informação nas redes sociais Twitter e Facebook.

Nas subseções seguintes descrevemos a arquitetura do Busão e detalhes da funcionalidade de pesquisa no sistema.

\subsection{Arquitetura}

O Busão foi projetado como um sistema cliente-servidor, permitindo facilidade de manutenção e alta disponibilidade da informação. Assim, a arquitetura do sistema foi dividida em três camadas: Camada de Aplicação, Camada de Lógica e Camada de Persistência. Na Figura 1, é ilustrada a arquitetura do Busão.

${ }^{3}$ https://www.institutoclaro.org.br/campusmobile/saiba_mais.php, acessado em 14 de janeiro de 


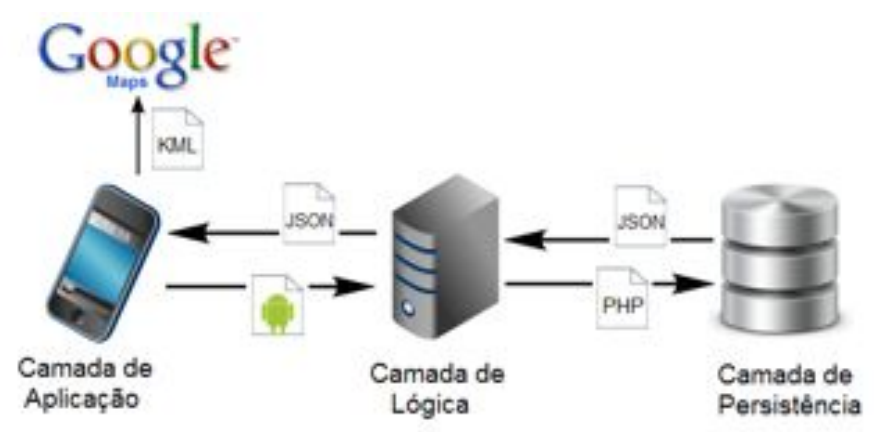

Figura 1. Arquitetura do Busão

A Camada de Aplicação, responsável pela interface visível ao usuário, oferece componentes para carga, manipulação e visualização de informações. A visualização dos dados espaciais (rotas dos ônibus) é redirecionada para o aplicativo Google Maps, nativo em smartphones com sistema Android. Ao iniciar o sistema, o mesmo captura a localização atual do usuário de forma automática. Essa localização é provida pelo GPS do smartphone, caso este esteja ativo; ou é solicitado a um serviço internet que determina a localização com base na disponibilidade de torre de celular e pontos de acesso sem fio. A Camada de Aplicação realiza as requisições de informações à Camada Lógica, manipulando a resposta em uma formatação adequada para assim ser exibida ao usuário.

A Camada de Lógica, por sua vez, é responsável pelo processamento de todas essas requisições enviadas pela Camada de Aplicação. Ao receptar uma requisição, a Camada de Lógica envia as solicitações de dados diretamente à Camada de Persistência, que interpreta e processa a solicitação gerando uma resposta à Camada de Aplicação. Em seguida, a Camada de Lógica reenvia a informação à Camada de Aplicação. Todo esse intercâmbio é realizado através do framework JSON [Zakas 2009].

A Camada de Lógica foi construída de forma a permitir que vários sistemas possam consumir a informação de maneira simples, utilizando requisições HTTP. A comunicação entre camadas de Aplicação e Lógica é realizada através de sockets, permitindo, assim, a troca de informações em tempo real. Para que essa comunicação seja realizada, é imprescindível que o celular tenha acesso à internet.

A Camada de Persistência é composta por um banco de dados objeto relacional com suporte espacial (PostGis/PostgreSQL). É de responsabilidade dessa camada o acesso, gestão e armazenamento e consultas espaciais dos dados.

\subsection{Projeto Conceitual do Banco de Dados Espacial Busão}

O banco de dados do Busão foi projetado com sete entidades, conforme diagrama apresentado na figura 2. A entidade Cidade representa os municípios com itinerários dos ônibus disponíveis no sistema e é espacialmente representada por um polígono. A entidade PontosTuristicos armazena espacialmente as localidades turísticas de cada cidade em forma de pontos. Essa entidade é importante para serem calculadas as rotas que passam por esses pontos de interesse. 
A entidade Empresa registra as empresas de cada cidade. Uma empresa possui várias concessões de rotas e é dona de veículos do tipo ônibus. A prefeitura demanda a quantidade de ônibus necessário para cada rota; esse mapeamento dos ônibus cadastrados no sistema com a rota que eles participam é armazenado no relacionamento Rota_has_Onibus.

A entidade Onibus armazena dados relativos aos veículos de cada cidade, incluindo a localização do mesmo, caso seja equipado com GPS.

A entidade Rota armazena informações relativas às rotas disponíveis na cidade. Uma rota cumpre vários horários, diferenciado pelos dias da semana. Uma rota é espacialmente armazenada com um linestring, uma cadeia de pontos interligados.

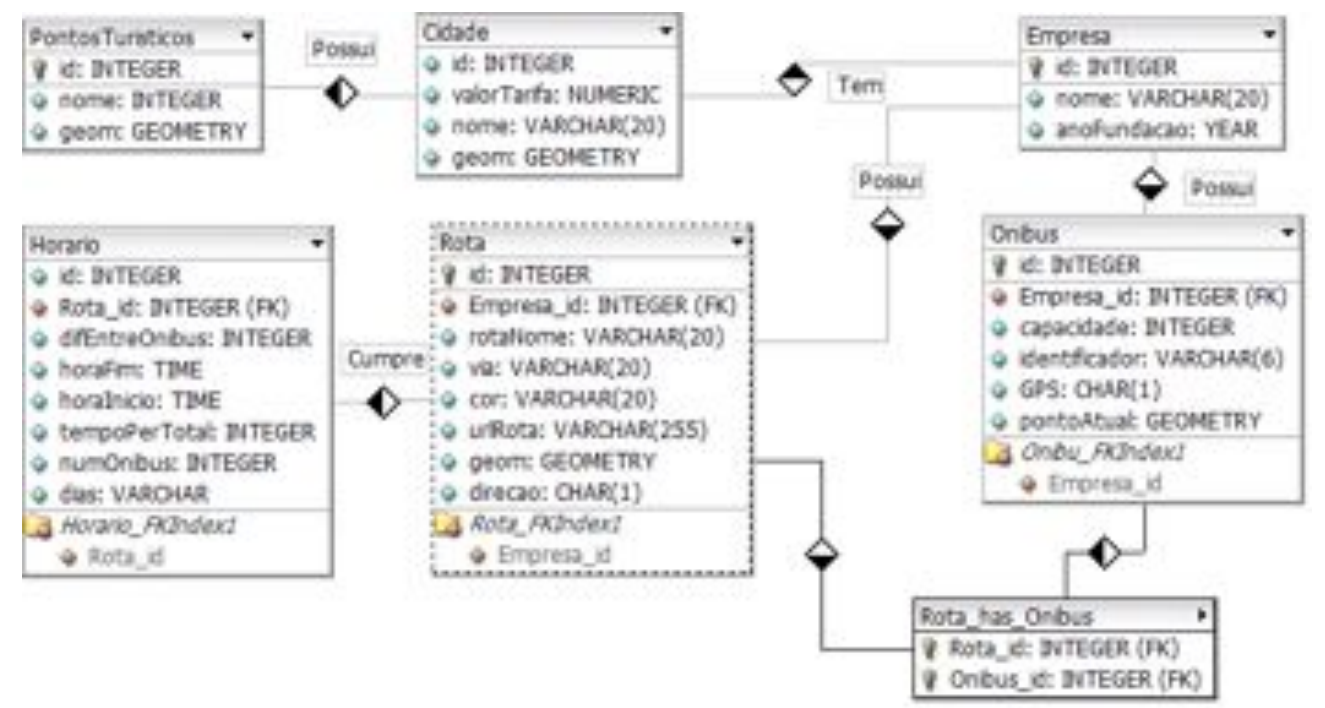

Figura 2. Projeto Conceitual do Banco de Dados do Busão

\subsection{A Funcionalidade Pesquisa}

Os usuários do Busão foram categorizados em: usuários frequentes e não frequentes. Os usuários frequentes são aqueles que estão familiarizados e utilizam o transporte coletivo como meio de locomoção, quase que diariamente. Os usuários não frequentes são aqueles que não têm informação alguma sobre as rotas que devem utilizar, porém necessitam de transporte público para realizar um dado deslocamento.

A partir desta classificação, foram desenvolvidas soluções apropriadas para cada classe de usuário. As duas operações de consulta providas pelo Busão são: Pesquisa por Linha e Pesquisa por Rotas. No restante desta seção, serão detalhadas cada tipo de consulta. Na figura 3, é apresentada a interface de cada modalidade de consulta.

\subsubsection{Pesquisa por Linha}

Neste tipo de pesquisa, o usuário fornece ao sistema a identificação da rota do ônibus desejado (i.e. 202, 550, 333), uma vez que cada rota de transporte público possui uma 
identificação única entre as rotas. A busca é realizada de forma exata e aproximada, a serem detalhadas mais adiante.

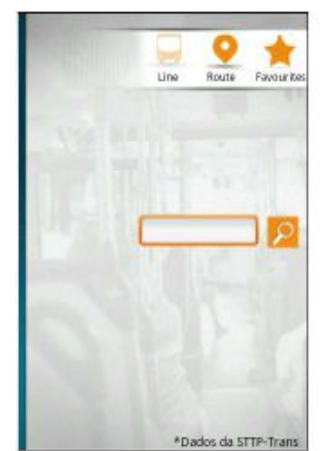

(a)

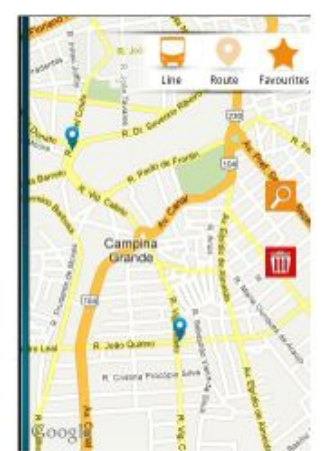

(b)

Figura 3. Pesquisa por Linhas (a) e Pesquisa por Pontos (b)

\subsubsection{Pesquisa por Pontos}

O usuário que não utiliza com frequência o transporte coletivo seja habitante da cidade ou turista, na maioria das vezes, não tem nenhuma informação sobre as rotas de ônibus. Normalmente, o usuário tenta extrair essas informações com outros usuários, o que não garante a consistência da mesma.

Nessa perspectiva, o Busão oferece um tipo de pesquisa que possibilita ao cidadão encontrar uma rota de ônibus que cobre determinado trecho. O usuário visualizará o mapa da cidade e será necessário que ele forneça dois pontos georreferenciados. Uma variação dessa pesquisa, é a possibilidade de utilizar o dispositivo de GPS, para fornecer um dos pontos requeridos pela pesquisa. Se apenas um ponto é marcado no mapa, o sistema entende que o usuário quer utilizar a posição atual do usuário fornecida pelo GPS, como seu segundo ponto de pesquisa.

Para melhorar a eficiência da consulta, o sistema acrescenta um raio de 300 metros aos pontos selecionados pelo usuário, através da função espacial ST_BUFFER do PostGis/PostgreSQL, para então verificar quais rotas cruzam os pontos georreferenciados, verificando, através da função espacial ST_CROSSES do PostGis/PostgreSQL, se a localização fornecida pelo usuário é comum a algum ponto da rota. Chegamos a esse valor de buffer, por achar que 300 metros seja uma distância razoável para um pedestre percorrer, em tempo hábil, a fim de alcançar uma parada de ônibus. Na figura, são apresentados o resultado de uma pesquisa e uma consulta espacial usando SQL. No exemplo da consulta SQL da figura 4, a tabela rotas é consultada, a função ST_ASKML, do Postgis/Postgresql, é utilizada para retornar a geometria da rota como um objeto KML e a função ST_BUFFER recebe dois atributos, o primeiro a geometria e o segundo o valor do buffer em graus (um grau corresponde a $111 \mathrm{~km}$ na linha do equador, daí o uso da constante 0,0027 que representa os 300 metros da consulta em graus). Por fim, a função ST_CROSSES recebe como parâmetro duas geometrias, e retorna verdadeiro caso as mesmas se cruzem em algum ponto, e falso, caso contrário. 

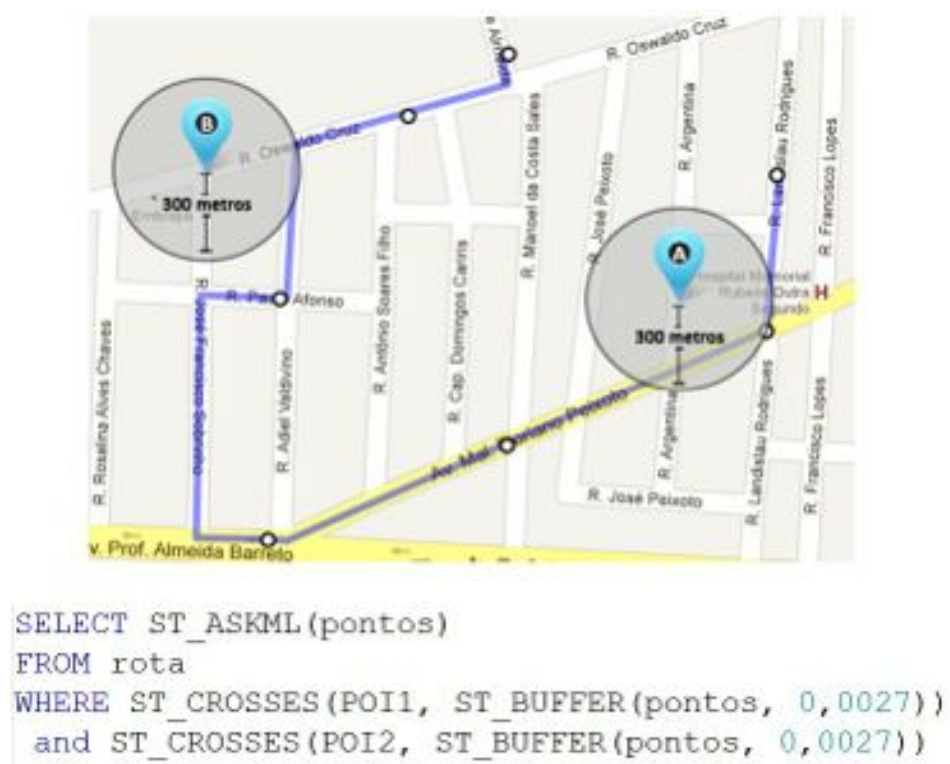

Figura 4. Funcionamento da Pesquisa por Pontos

\subsubsection{Resultado da Pesquisa}

Em ambos os tipos de pesquisa há três possibilidades de resposta do sistema:

- A rota não existe - $A$ rota pesquisada não existe. $O$ identificador fornecido na busca não existe ou nenhuma rota cruza o buffer dos dois pontos. O usuário é informado disso e redirecionado para realizar uma nova busca.

- Busca Aproximada - Nesta situação, o usuário recebe uma lista de rotas ordenadas pela proximidade em relação à posição atual do usuário - em que os identificadores da mesma contêm todo ou parte do identificador pesquisado ou várias rotas cruzam os dois pontos selecionados. Fica sob a responsabilidade do usuário a escolha da rota que deseja visualizar.

- Busca Exata - Apenas uma rota é encontrada, ou pelo identificador único ou somente uma rota cruza os pontos fornecidos. O sistema apresentará a tela padrão, onde as informações sobre a rota pesquisada são exibidas.

Ao ser escolhida uma rota para visualização, o usuário é redirecionado para uma página de exibição de informações básicas sobre as rotas, tais como: hora de início e término da rota, o número de ônibus participantes da linha e o tempo aproximado para a próxima parada da linha. Em seguida, o aplicativo será redirecionado para o Google Maps, que ilustra, num mapa, o trajeto daquela linha. Na figura 5, é apresentada a interface de visualização das informações sobre as rotas, com destaque para o tempo restante para a passagem do próximo ônibus. 


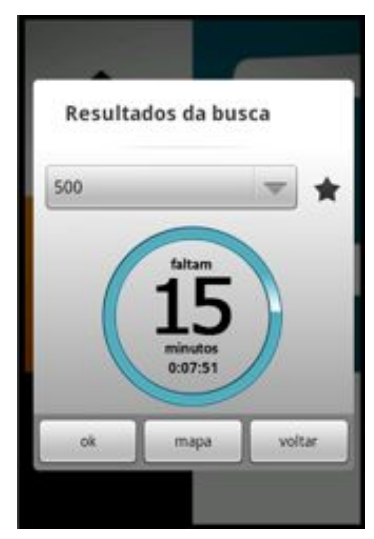

Figura 5. Visualização das informações básicas sobre uma dada rota de ônibus.

O tempo aproximado para a próxima parada $(\mathrm{TR}(\mathrm{x}))$ é calculado utilizando a equação 1. É importante frisar que o cálculo só será realizado caso o usuário esteja em uma localização que é coberta pela rota - considera-se, novamente, o buffer -. Essa condição é verificada antes do cálculo ser efetivamente realizado.

$$
T R(x)=[(h A-h l(x)) \%(t P T(x))] \% i R(x)
$$

Onde hA representa a hora atual, fornecida pelo próprio smartphone; $\mathrm{hl}(\mathrm{x})$ fornece a hora inicial de operação da rota $\mathrm{x}$; $\operatorname{tPT}(\mathrm{x})$ retorna o tempo total que a rota $\mathrm{x}$ leva para percorrer todo o seu percurso e $\mathrm{iR}(\mathrm{x})$ é a função que fornece o intervalo entre dois ônibus da rota $\mathrm{x}$.

Ao optar pela visualização do percurso da rota, o sistema enviará para o aplicativo Google Maps do smartphone o KML (linguagem XML que facilita a manipulação de anotações geográficas e exibição de mapas $2 \mathrm{D}$ e $3 \mathrm{D}$ ) representativo da rota ativa. $\mathrm{Na}$ figura 6, é exemplificada uma instância de um objeto KML utilizado no Busão.

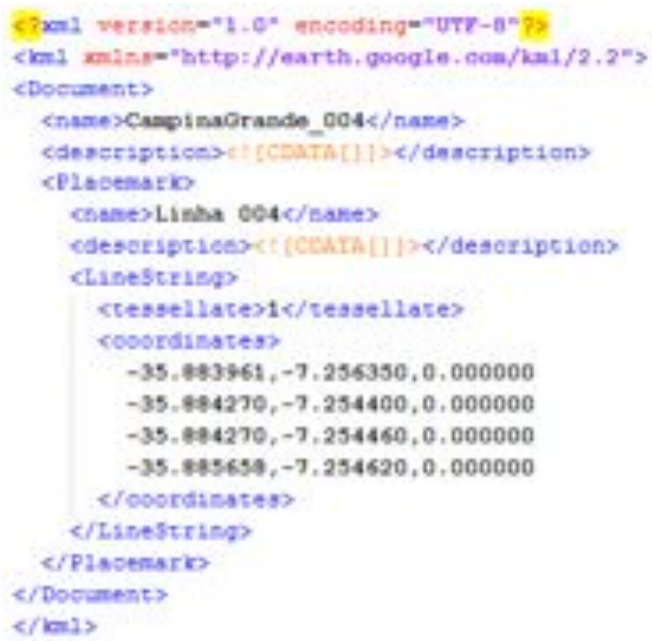

Figura 6. Exemplo de KML 


\section{Estudo de Caso}

O Busão foi testado, como prova de conceito, na cidade de Campina Grande, Paraíba. Os dados utilizados pelo aplicativo Busão foram fornecidos pelo órgão regulador do transporte público da Prefeitura de Campina Grande (Superintendência de Trânsito e Transportes Públicos - STTP). A STTP repassou os dados de todas as rotas pertencentes a Campina Grande, em arquivos textuais com extensão .doc. Cada arquivo continha informações sobre identificação da rota, concessionária responsável, horários de início e término de circulação, intervalo entre ônibus, dias de funcionamento e ruas abrangidas pela rota. Os dados espaciais obtidos passaram por uma etapa de transformação, na qual para cada rota, foi gerado um arquivo KML, a fim de facilitar a exibição posterior das rotas no aplicativo do Google Maps nativo nos smartphones. Para isso, foi utilizada uma API nativa do Google Maps, que permite o desenho de qualquer trajeto pelas ruas.

Essa metodologia foi pensada porque caso ocorra uma alteração no trajeto de uma determinada rota, pelo órgão responsável, faz necessário apenas alterar o desenho na própria API do Google Maps, atualizar o arquivo KML e recarregar as informações no banco de dados, facilitando a manutenção e consistência dos dados armazenados.

A partir dessas informações, foi criado um banco de dados espacial, objeto relacional, a partir do mapeamento do esquema conceitual apresentado na figura 2 . O sistema de gerenciamento de banco de dados utilizado foi o PostGis/PostgreSQL. Posteriormente, fez-se a carga destes dados. Ao todo, o banco de dados do estudo de caso possui quarenta e quatro rotas e cerca de duzentos ônibus cadastrados.

A princípio, o Busão foi submetido à avaliação de 15 pessoas, que utilizam diversos tipos de smartphones operados com o sistema Android na versão 2.2 ou superior, sendo $80 \%$ deles do sexo masculino e todos na faixa etária entre 18 e 29 anos. Ao serem questionados sobre há quanto tempo eles utilizam o transporte coletivo na cidade de Campina Grande e seu grau de satisfação quanto ao mesmo, observou-se que mesmo os usuários que utilizam o transporte coletivo há menos do que 06 (seis) meses, já estão pouco satisfeitos com o sistema, opinião que vai sendo mantida e intensificada com o tempo de utilização do transporte coletivo. Entretanto, os usuários que utilizam o transporte coletivo há mais que cinco anos, já não demonstram nenhum tipo de satisfação com a infraestrutura de transporte coletivo. Na Tabela 2, são apresentados mais detalhes sobre o grau de satisfação dos usuários.

Tabela 2. Tempo de Utilização vs Grau de Satisfação

\begin{tabular}{c|cccccc}
\hline $\begin{array}{c}\text { satisfação } \\
\text { tempo }\end{array}$ & $\begin{array}{c}\text { Muito } \\
\text { Insatisfeito }\end{array}$ & $\begin{array}{c}\text { Pouco } \\
\text { Insatisfeito }\end{array}$ & Neutro & $\begin{array}{c}\text { Pouco } \\
\text { Satisfeito }\end{array}$ & $\begin{array}{c}\text { Muito } \\
\text { Satisfeito }\end{array}$ & Total \\
\hline $\begin{array}{c}\leq 66 \\
\text { meses }\end{array}$ & - & $6,68 \%$ & $13,35 \%$ & $6,67 \%$ & - & $26,7 \%$ \\
$\begin{array}{c}\text { Entre 2 e 5 } \\
\text { anos }\end{array}$ & $6,65 \%$ & $6,65 \%$ & - & $20 \%$ & - & $33,3 \%$ \\
$\geq 05$ anos & $13,33 \%$ & $13,34 \%$ & $13,33 \%$ & - & - & $40 \%$ \\
Total & $19,98 \%$ & $26,67 \%$ & $26,68 \%$ & $26,67 \%$ & - & $\mathbf{1 0 0} \%$ \\
\hline
\end{tabular}


Ao serem questionados com relação à precisão (engloba a eficiência da pesquisa, a exibição no mapa e o tempo estimado para o próximo ônibus) que $o$ sistema Busão apresenta, os resultados foram satisfatórios, uma vez que os ônibus não dispõem de GPS para informar, com exatidão, a atual localidade do mesmo. Esse resultado corrobora com a fórmula desenvolvida (equação 1) para calcular o tempo aproximado para a próxima parada. Na figura 7 são apresentados os dados relacionados à precisão do Busão.

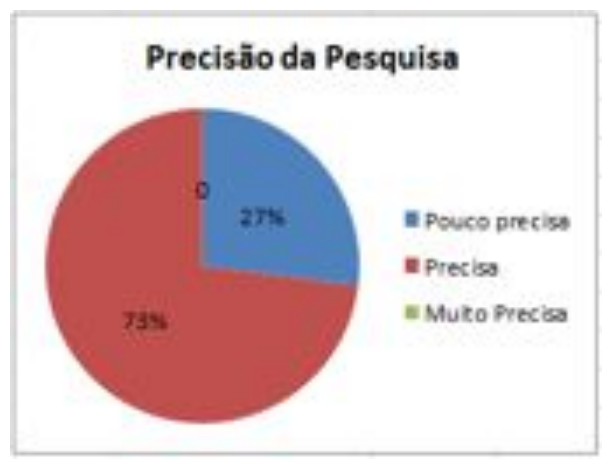

Figura 7. Precisão da Pesquisa do Busão

\section{Conclusões e Trabalhos Futuros}

Este artigo apresentou uma visão geral do Busão, um SIU que visa melhorar a experiência do usuário de transportes coletivos em aglomerados urbanos. Como trabalho futuro, o aplicativo será adaptado para integração das rotas de diversas cidades. Além disso, será implementada a funcionalidade de transportes multimodais, ou seja, a articulação entre vários modos de transporte, de forma a tornar mais rápida e eficaz a mobilidade da população. Outro ponto que será explorado em trabalhos futuros é a utilização de técnicas de crowdsourcing - metodologia na qual as pessoas são consideradas sensores nas soluções de Cidades Inteligentes -, consumindo informações provenientes de redes sociais.

\section{Referências Bibliográficas}

Sussman, J. Perspectives on Intelligent Transportation Systems. Springer, New York, USA, 2005.

Wilson, N. The Role of Information Technology in Improving Transit Systems in Transportation@MIT Seminar, Boston, USA, 2009.

Naphade M., Banavar G., Harrison C., Paraszczak J.; Morris R.; Smarter Cities and Their Innovation Challenges. June, 2011

Schein, A. L., "Sistema de Informação ao Usuário como estratégia de fidelização e atração". 148f. Dissertação - Departamento de Engenharia de Produção, Universidade Federal do Rio Grande do Sul, Porto Alegre-RS, 2003 
Vieira, V., Salgado, A. C., Tedesco P., Times, V. C., Ferraz, C., Huzita, E., Chaves, A. P., Steinmacher, I. The UbiBus Project: Using Context and Ubiquitous Computing to build Advanced Public Transportation Systems to Support Bus Passengers. In: Anais do VIII Simpósio Brasileiro de Sistemas de Informação, 2012, São Paulo.

Lima, V. G., Magalhães, F., Tito, A. O., Santos, R., Ristar, A., Santos, L., Vieira, V., Salgado, A. C. (2012) UbibusRoute: Um Sistema de Identificação e Sugestão de Rotas de Ônibus Baseado em Informações de Redes Sociais. In: VIII Simpósio Brasileiro de Sistemas de Informação (SBSI) - Cidades Inteligentes, São Paulo.

Liu, B., Wang, W., Travel time enabled bus route navigation system experiment in Beijing. In: Proceedings of the 2007 IEEE Intelligent Transportation Systems Conferece, Seattle, WA, USA, Sept. 30 - Oct. 3, 2007.

Amorim A. M., Campos J. A conceptual Model for Representation of Taxi Trajectories. In: XIII Brazilian Symposium on GeoInformatics, Campos do Jordão, 2012.

Ferris, B., Watkins, K., Borning, A. (2010) "Location-Aware Tools for Improving Public Transit Usability."IEEE Pervasive Computing.Vol. 9 no.1, pp. 13-19. Jan-Mar 2010.

Chakchai, So-In,Poolsanguan, S., Poonriboon, C., Veeramongkonleod, N. Ubiquitous Bus Mapping System on Mobile Phone via Web Architecture.In Computer Applications and Industrial Electronics (ICCAIE), 2011 IEEE International Conference on December 2011.

Zakas, N. C. Professional JavaScript for Web Developers. Wrox, 3rd Edition, 2012. 